\title{
BIBLIOGRAFIA DEL INDIGENISMO HISPANOAMERICANO
}

\author{
POR \\ DAVID WILLIAM FOSTER \\ Arizona State University
}

Esta recopilación asienta la producción creativa - tanto ficticia como ensayística- de las figuras más descollantes del indigenismo en Hispanoamérica. Debido a severas limitaciones de espacio, este registro se circunscribe solamente a aquellos escritores cuya obra puede decirse sirve como punto focal de dicha manifestación cultural. Asimismo, los asientos críticos sobre su escritura se limitan a aquellos estudios monográficos y ensayos que informan directamente sobre cuestiones del indigenismo o cuestiones paralelas a las obras señeras del mismo.

Dos observaciones en cuanto al formato adoptado. Las antes mencionadas limitaciones de espacio han impedido el análisis de colecciones de ensayos sobre los varios autores; el título de éstas queda asentado como estudio monográfico. Aunque, como regla general, no se da cuenta de reseñas de las obras, se han incluido algunas referencias importantes debido al crítico que las ha firmado o a la revista donde aparecen; estas reseñas van con el título de la obra reseñada entre corchetes.

Quiero reconocer los valiosos aportes a esta recopilación, realizada por encargo en pocos meses, de mi ayudante Iusta Zoila Gamero Abarca de Tovar.

\section{REFERENCIAS GENERALES}

Abellán, José Luis. «Los orígenes españoles del mito del 'buen salvaje': Fray Bartolomé de las Casas y su antropología utópica». Revista de Indias, núms. 145-146 (1976), 157-159.

Aguirre Beltrán, Gonzalo. «Indigenismo y mestizaje: una polaridad biocultural». Cahiers d'Histoire Mondiale, 6, 1 (1960), 158-171. 
Aldrich, Earl M. Regionalismo e indigenismo. Madrid: La Muralla, 1980. Amauta. Lima, 1926-1930.

Antropología e indigenismo na América latina. São Paulo: Cortez, 1981.

Aquézolo Castro, Manuel. La polémica del indigenismo. Lima: Mosca Azul, 1976.

Arguedas, José María. Señores e indios: acerca de la cultura quechua. Introducción de Angel Rama. Montevideo: Arca, 1976?

Arias-Larreta, Abraham. «Definición del indigenismo peruano». Nueva Democracia, 36, 3 (1956), 36-42.

- «Presencia y actitud del nativo en la novela peruana». América, 44, 1 (1954), 14-26.

Ballesteros Gaibrois, Manuel. Indigenismo americano. Madrid: Cultura Hispánica, 1961.

Bareiro Saguier, Rubén. «El indigenismo en las novelas de la guerra del Chaco". Travaux de l'Institut de Études Latino-Américaines de l'Université de Strasbourg, 5 (1965), 127-134.

Barreda Tomás, Pedro M. «El indianismo y el indigenismo en la narrativa hispanoamericana: estudio de algunas de sus confluencias». En Libro de homenaje a Luis Alberto Sánchez... (Lima: Universidad Mayor Nacional de San Marcos, 1967), pp. 45-61.

Cazes, Daniel. «Indigenismo en México: pasado y presente». Historia y Sociedad, 5 (1966), 66-84.

Cerruti, Franco. «Il mondo indigeno nella poesia nicaraguense contemporanea». Terra Ameriga, 4, 13 (1968), 18-28.

Chang-Rodríguez, Eugenio. «Reseña histórica del indigenismo». Cuadernos del Congreso por la Libertad de la Cultura, núm. 17 (1956), 61-69.

—. «Variaciones sobre el indigenismo». Nueva Democracia, 36, 1 (1956), 96-111.

Codina, Iverna. «Perú y la reivindicación del indio». En su América en la novela (Buenos Aires: Cruz del Sur, 1964), pp. 119-127.

Comas, Juan. Ensayos sobre indigenismo. México, D. F.: Instituto Indigenista Interamericano, 1953.

- «Panorama continental del indigenismo». Cuadernos americanos, número 54 (1950), 147-166.

Cometta Monzoni, Aída. El indio en la novela de América. Buenos Aires: Futuro, 1960.

- El indio en la poesía de América española. Buenos Aires: Joaquín Torres, 1939.

- _. «El problema del indio en Bolivia y su proyección en la novela». Atenea, núm. 200 (1942), 142-170.

Cornejo Polar, Antonio. «El indigenismo y las literaturas heterogéneas: su doble estatuto social-cultural». Revista de Critica Literaria Latinoamericana, núms. 7-8 (1978), 7-21.

- «La novela indigenista: un género contradictorio». Toxto crítico, número 14 (1979), 58-70. 
—. «Para una interpretación de la novela indigenista». Casa de las Américas, núm. 100 (1977), 40-48.

- - "Sobre el modo de producción de la literatura indigenista». En Homenaje a Jorge Basadre (Lima: Pontificia Universidad Católica del Perú, 1978), II, 51-59.

Corrales, Manuel. «Las raíces del relato indigenista ecuatoriano». Revista de Crítica Literaria Latinoamericana, núms. 7-8 (1978), 39-52.

Corsun, Norma Klahn. «La imaginación mestiza en la novela mexicana contemporánea». Dissertation abstracts internacional, 39 (1978), 2963 A.

Coulthard, G. R. «El mito indígena en la literatura hispanoamericana contemporánea». Cuadernos Americanos, núm. 156 (1968), 164-173.

Cueva, Agustín. «En pos de la historicidad perdida: contribución al debate sobre la literatura indigenista del Ecuador». Revista de Crítica Literaria Latinoamericana, núms. 7-8 (1978), 23-38.

Díaz-Polance, Héctor. «Indigenismo, populismo, and marxismo». Latin American Perspectives, 9, 2 (1983), 42-61.

Díaz Rozzotto, J. «Ponencia sobre negritud e indigenismo - ritmo y tiempo». Cuadernos Americanos, núm. 198 (1974), 31-42.

Echevarría, Evelio. «Panorama y bibliografía de la novela social boliviana». Inter-American Review of Bibliograph, 27, 2 (1977), 143-152.

Escajadillo, Tomás Gustavo. La narrativa indigenista: un planteamiento y ocho incisiones. Disertación inédita, Universidad Nacional Mayor de San Marcos, 1971.

Falla, Ricardo. «El movimiento indígena». Estudios Centroamericanos, números 356-357 (1978), 437-461.

Febres Cordero, G. Julio. "Balance del indigenismo en Cuba». Revista de la Biblioteca Nacional [Cuba], 2. ${ }^{a}$ serie, 1, 4 (1950), 61-204.

Fortún, Julia Elena. "Nuevo enfoque del indigenismo». América Indígena, 31 (1971), 911-915.

Franco, V. de. «El indigenismo y su expresión literaria». En Australasian Universities Language and Literature Association, Proceedings and Papers of the Thirteenth Congress... (Melbourne: AULLA and Monash University, 1971), pp. 486-487.

Fuller, O. T. «Observador, echa una ojeada al indigenismo». América Indígena, 33 (1973), 355-374.

Gallegos, Gerardo. «¿Dónde están los personajes de la novela indoamericana?». Universidad de Antioquía, 8 (1939), 85-88.

García, José Uriel. El nuevo indio; ensayos indianistas sobre la sierra peruana. 2. ${ }^{a}$ ed. corregida. Cuzco: H. G. Rozas, 1937. Orig. 1930.

Garscha, Karsten. «Indianer in Peru. Der Indigenismus als Thema des Spanischunterrichts». Paedagogie der Fremdsprachliche Unterricht, 15 (1891), 105-115.

Gold, Peter J. «Indianismo and indigenismo». Romance Notes, 14 (1973), 460-464. 
González-Gerth, Miguel, «Themes and Images of the Indian in Spanish American Literature: an Overview». Papers in Contemporary Literature, 3, 2 (1977), 12-20.

González Prada, Manuel. Nuestros indios. México, D. F., 1978.

Grossman, Rudolf. «Der Indio in Dichtung und Erzahlungskunst de Lateinamerikaner: Fiktion und Wirklichkeit». Romanistisches Jahrbuch, 26 (1975), 326-342.

Guatemala indigena. Guatemala: Instituto Indigenista Nacional, 1961.

Guillén Tamayo, Andrés. «Lo mestizo y el indigenismo». Revista Universitaria [Cuzco], núm. 96 (1948), 214-223.

Gullón, Ricardo. «Indigenismo y modernismo». En Homero Castillo, Estudios criticos sobre el modernismo (Madrid: Gredos, 1974), pp. 267-278.

Indígena. Berkeley, Calif., 1974.

Indigenismo y autogestión: coloquio sobre indigenismo... Caracas: Monte Avila, 1980.

«Indigenismo y desarrollo». América Indígena, 40 (1980), 423-428.

Jornadas Americanistas, III, Valladolid, 1974. Estudios sobre politica indigenista española en América. Valladolid: Universidad de Valladolid, Seminario de Historia de América, 1975.

Junco, Alfonso. «Indigenismo hispánico». Boletín de la Academia Hondureña, 5, 6 (1959), 144-147.

Klaiber, Jeffrey L. Religion and Revolution in Peru: 1824-1976. Notre Dame: University of Notre Dame Press, 1977.

Lannoy, Jean-Louis $M$. de. «Indigenisme et littérature indianiste au Mexique et au Pérou». NS/Northsouth, 3, 5-6 (1978), 138-156.

Lazo, Raimundo. La novela andina; pasado y futuro. México, D. F.: Porrúa, 1971.

Leal, Antonio A.: «La novela indigenista en México». Círculo, 2 (1970), 184188.

León Portilla, Miguel. «Trauma cultural, mestizaje e indigenismo en Mesoamérica». Cuadernos Americanos, núm. 201 (1975), 113-133.

Lipschutz, Alejandro. El indoamericanismo y el problema racial en las Américas. Santiago, Chile: Andrés Bello, 1967.

- Perfil de Indoamérica de nuestro tiempo. La Habana: Instituto Cubano del Libro, 1972.

Lorand de Olazagasti, Adelaide. El indio en la narrativa guatemalteca. San Juan, P. R.: Universitaria, 1968.

Macero dall'Orso, Pablo. «Reflexiones a propósito de la polémica del indigenismo». Apuntes, 3, 6 (1977), 75-81.

Madrid. Universidad. Seminario de Estudios Americanistas. Trabajos y conferencias. Madrid, 1952-1961.

Mahn-Lot, Marianne. «Espagne et indigenisme en Amérique». Revue d'Histoire Moderne et Contemporaine, 28, 2 (1981), 293-303.

Mantilla Pineda, Benigno. «Sociología de la novela indigenista». Universidad de Antioquía, núm. 170 (1968), 955-979. 
Mariátegui, José Carlos. 7 ensayos de interpretación de la realidad peruana. Lima: Biblioteca Amauta, 1928.

Marín, Gladys C. «Presencia estructural del pensamiento indígena en la cultura americana». En América latina: integración por la cultura (Buenos Aires: García Cambeiro, 1977), pp. 83-106.

Martí, Jorge L. «Consideraciones sobre la novela indianista». La Torre, número 58 (1967), 187-201.

Marzal, Manuel María. Historia de la antropología indigenista: México y Perú. Lima: Pontificia Universidad Católica de Perú, 1981.

McDonald, James K. «Motivos autóctonos en el pensamiento ensayístico de México en el siglo xx». Dissertations Abstracts International, 30 (1970), $4459 \mathrm{~A}$.

McMahon, Dorothy. "The Indian in Romantic Literature of the Argentine». Modern Philology, 56 (1958), 17-23.

Meinhardt, Warren Lee. «The Mexican Indianist Novel: 1910-1960». Dissertation Abstracts International, 26 (1966), 3958.

Meléndez, Concha. «La literatura indianista en el Perú de hoy». En Memoria, Primer Congreso Internacional de Catedráticos de Literatura Iberoamericana (México, D. F.: Universidad Nacional Autónoma de México, 1939), pp. 99-109. También en su Asomante (San Juan, P. R.: Cordillera, 1970), pp. 59-72.

—. La novela indianista en Hispanoamericana: 1832-1889. Río Piedras, P. R.: Universidad de Puerto Rico, 1961. Orig. 1932.

Memorias del Instituto Nacional Indigenista: métodos y resultados de la política indigenista en México. México, D. F.: Instituto Nacional Indigenista, 1954.

Menton, Seymour. «La novela del indio y las corrientes literarias». En Homenaje a Luis Leal; estudios sobre literatura hispanoamericana (Madrid: Insula, 1978), pp. 63-73.

Montoya Briones, José de Jesús. «Hacia un nuevo planteamiento y fundamentación del indigenismo». América Indígena, 33 (1973), 13-43.

Moraña, Mabel. «Función ideológica de la fantasía en las novelas de Manuel Scorza». Revista de Crítica Literaria Latinoamericana, núm. 17 (1983), 171-192.

Moretić, Yerko. «Tras las huellas del indigenismo literario en el Perú». En Recopilación de textos sobre José María Arguedas (La Habana: Casa de las Américas, 1976), pp. 31-44.

Muñoz, Braulio. Sons of the wind: the search for identity in Spanish American Indian literature. New Brunswick, N. J.: Rutgers University Press, 1982.

Nahmad, Salomon. "Las ideas del positivismo en el indigenismo de la época pre-revolucionaria en México». América Indígena, 33 (1973), 1169-1182.

Noel, Martín Abel. «El indigenismo en la literatura peruana del siglo XX». Letras de Buenos Aires, 2, 5 (1981), 15-25. 
Nolasco, Margarita. «América: indios, indigenismo y política». INAH Anales, núm. 52 (1975), 303-345.

Norris, Robert E. «El novelista latinoamericano frente a la realidad indígena contemporánea». Revista de la Casa de la Cultura Ecuatoriana, 24 (1966), 175-211.

Noticias indigenistas de América. México, D. F., 1979.

Núñez, Estuardo. «Expresionismo en la poesía indigenista del Perú». Spanish Review, 2, 2 (1935), 69-80.

- Panorama actual de la poesía peruana. Lima: Antena, 1938. Véase sección sobre «Expresionismo indigenista».

Orbe, Gonzalo Rubio. «Argentina indígena». América Indígena, 33 (1973), 643-654.

—. «México indígena». América Indígena, 33 (1973), 931-957.

Oppens, Edith. Die Entrechteten: indianisches Schicksal in den Andenlandern im Spiegel der Literatur. Hamburg: Ubersee-Verlag, 1965.

Ortega, José. "Indigenismo y alienación en las letras bolivianas». Chasqui, 6, 3 (1977), 27-36.

Ortiz de Montellano, Bernardo. La poesía indigena de México. México, D. F.: Talleres Gráficos de la Nación, 1936.

Othón de Mendizábal, Miguel. «Indigenismo y antropología en América». Boletín de Educación Paraguaya, núm. 1 (1980), 168-174.

Pacheco, José Emilio. «La patria perdida: notas sobre Clavijero y la cultura nacional». En Héctor Aguilar Camín y otros. En torno a la cultura nacional (México, D. F.: Secretaría de Educación Pública; Instituto Indigenista, 1976), pp. 15-50.

Pamies, Alberto N. «Negrigenismo: génesis y dirección». En Homenaje a Lydia Cabrera (Miami: Universal, 1978), pp. 309-316.

Paoli, Roberto, y Antonio Cornejo Polar. «Sobre el concepto de heterogeneidad: a propósito del indigenismo literario». Revista de Crítica Literaria Latinoamericana, núm. 12 (1980), 257-267.

El pensamiento indigenista. San Isidro, Perú: Campodónico, 1981.

Pérez, Galo René. "La novela indigenista hispanoamericana». Inter-American Review of Bibliography, 23, 3 (1973), 302-318.

Pérez Cadalso, Eliseo. «José Cecilio del Valle: precursor indigenista». Boletín de la Academia Hondureña de la Lengua, 22, 22 (1979), 115-126.

La polémica del indigenismo. Lima: Mosca Azul, 1963.

Portal, Marta. «Narrativa indigenista mexicana de mediados de siglo». Cuadernos Hispanoamericanos, núm. 298 (1975), 196-207.

Queiroz, María José de. Do indianismo ao indigenismo nas letras hispanoamericanas. Belo Horizonte: Imprensa de Universidade de Minas Gerais, 1962.

—. "O indigenismo paraguaio». Minas Gerais, Suplemento Literário, 9-IX1972, p. 4.

Rama, Angel. «El área cultural andina (hispanismo, mesticismo, indigenismo». Cuadernos Americanos, núm. 196 (1974), 136-173. 
- - Transculturación narrativa en América latina, México, D.F.: Siglo XXI, 1982.

Reinaga, Fausto. El indio y los escritores de América. La Paz, PIB, 1969.

Ribeiro, Darcy. «Etnicidade, indigenato e campesinato». Vozes, 73, 8 (1979), 5-18.

-. "Os protagonistas do drama indígena». Vozes, 71, 6 (1977), 5-20.

Roberts, William H. «Hacia una tradición indígena en la poesía paraguaya». Hispanófila, núm. 13 (1961), 33-43.

Rodríguez-Luis, Julio. Hermenéutica y praxis del indigenismo: la novela indigenista, de Clorinda Matto a José María Arguedas. México, D. F.: Fondo de Cultura Económica, 1980.

Kojas, Angel F. La novela ecuatoriana. México, D. F.: Fondo de Cultura Económica, 1948. Véanse secciones sobre indigenismo.

Rojas, Ricardo. «El indio en el teatro». Revista de Indias, segunda época, núm. 25 (1941), 185-192.

Rojas Garcidueñas, José. «Indigenismo en el México de los siglos XVII a XIX»». Revista de la Universidad de México, 30, 7 (1976), 1-7.

Sacoto Salamea, Antonio. El indio en el ensayo de la América española, Cuenca, 1981.

Sáenz, Moisés. Sobre el indio ecuatoriano y su incorporación al medio nacional. México, D. F.: Secretaría de Educación Pública, 1933.

Saint-Lu, André, «Fondements et implications de l'indigenisme militant de Bartolomé de las Casas». Jahrbuch für Geschichte von Staat, Wirtschaft und Gesellschaft Lateinamerikas, 14 (1977), 47-56.

Salazar Bondy, Sebastián. «La evolución del llamado indigenismo». Sur, número 293 (1965), 44-50.

Sánchez, Luis Alberto. «El indianismo literario: ¿tendencia original o imitativa?». Revista Nacional de Cultura, num. 138 (1960), 107-117.

- - «La novela social. II: Novela antiimperialista. Novela indigenista». En su Proceso y contenido de la novela hispano-americana. 2. ${ }^{a}$ ed., corregida y aumentada (Madrid: Gredos, 1968), pp. 481-512.

Scheben, Helmut. «Indigenismo y modernismo». Revista de Crítica Literaria Latinoamericana, núm. 10 (1979), 115-128.

Schmidt, Donald L. "Changing narrative techniques in the Mexican indigenista novel». Dissertation Abstracts International, 33 (1972), 2951A-2952A.

- - "The indigenista novel and the Mexican revolution». The Americas, 33 (1977), 652-660.

Serbín, Andrés. «Etnicidad y política: los movimientos indígenas en América latina». Nueva sociedad, núm. 49 (1980), 57-71.

Siverts, Henning. «Mexican indians and 'indigenismo'». Folk, $19-20$ (19771978), 113-132.

Sivirichi, Atilio. «E1 contenido espiritual del movimiento indigenista». Revista Universitaria [Cuzco], 26 (1937), 1-23.

Skinner-Klee, Jorge. Recopilación de la legislación indigenista de Guatemala. México, D. F.: Instituto Indigenista Inter-Americano, 1954. 
Sommers, Joseph. «Changing views of the Indian in Mexican literature». Hispania, 47 (1964), 47-55.

- - «El ciclo de Chiapas: nueva corriente literaria». Cuadernos Americanos, núm. 133 (1964), 246-261.

- «The Indian-oriented novel in Latin American: new spirit, new forms, new scope». Journal of Inter-American studies, 6, 2 (1964), 249-265.

Sorel, Andrés. "La nueva novela indígena». En Julio Flores V. José María Arguedas y la nueva novela indígena del Perú (Valparaíso: Revista «Coral», 1970), pp. 15-18.

Southard, Gordon D. La novela indigenista en Hispanoamérica. Disertación inédita, University of Chicago, 1959.

Stratton, Marian Joyce Elaine. «The ideology of the Indian reform movement in eighteenth-century Peru». Dissertation Abstracts International, 39 (1978), 306 A-307 A.

Tamayo, José Armando. Historia del indigenismo cuzqueño, siglos XVI-XX. Lima: Instituto Nacional de Cultura, 1980.

—_. «El indigenismo peruano y 'El padre Horán' de Narciso Aréstegui». Letras [Lima], núms. 70-71 (1963), 70-83.

- «Persistencia del indigenismo en la narrativa peruana». Cuadernos Hispanoamericanos, núm. 350 (1979), 367-377.

Tapia, John Reyna. The Indian in the Spanish-American novel. Washington, D. C.: University Press of Americana, 1981.

Tauro, Alberto. «Antecedentes y filiación de la novela indianista». Mar del Sur, 1, 2 (1948), 29-40.

- «Presencia y definición del indigenismo literario». Tres, núm. 8 (1941), 67-83. También en Memoria, Primer Congreso Internacional de Catedráticos de Literatura Iberoamericana (México, D. F.: Universidad Nacional Autónoma de México, 1939), pp. 369-386.

Thompson, Judith Lee Warwick. «The evolution of the Mexican indigenist narrative in the twentieth century». Dissertation Abstracts International, 47 (1980), 2136 A-37 A.

Tilles, Solomon H. «Indianismo in the Spanish American novel». Dissertation Abstracts International, 30 (1969), 738 A.

Torre, Guillermo de. «Indigenismo, americanismo, europeísmo». En su Claves de la literatura hispanoamericana (Buenos Aires: Losada, 1968), pp. 65-71.

Tritten, Susan. «The social quest of the mestizo». Dissertation Abstracts International, 40 (1979), 2086 A.

Urbanski, Edmund Stephen. "The Indian in Latin American fiction». Américas, 15, 5 (1963), 20-24. Existen también versiones en español y portugués.

Urello, A. «Antecedentes del neoindigenismo». Cuadernos Hispanoamericanos, núm. 268 (1972), 5-25.

Vaca Guzmán, Santiago: «La raza quechua y la raza castellana y su influencia en las letras bolivianas». Kollasuyo, 1, 1 (1939), 56-65; 1, 2 (19...), $59-65$. 
Valcárcel, Luis Enrique. «El indigenismo peruano». América Indígena, 35 (1975), 247-250.

-_. «El indio en nuestra literatura». Cuadernos del Congreso por la Libertad de la Cultura, núm. 19 (1956), 99-103.

Varela, José Luis. Ensayos de poesía indígena en Cuba. Madrid: Cultura Hispánica, 1951.

Varese, Stefano. «Indianidad y proyecto civilizatorio en Latinoamérica». Revista Mexicana de Ciencias Sociales, Nueva época, núm. 97 (1979), 161176.

Vasconcelos, José. Indología. Barcelona: Agencia Mundial de Librería, 1927?

- La raza cósmica. Barcelona, 1925.

Velasco Toro, José. «Indigenismo y rebelión totonaca de Papantia, 18851896». América Indígena, 39 (1979), 81-105.

Voudouris, Arthur C. «The Indian in the Bolivian novel 1904-1965». Dissertation Abstracts International, 33 (1972), 2347 A-2348 A.

Wade, Gerald E., y William H. Archer. "The Indianist novel since 1889». Hispania, 33 (1950), 211-220.

Wogan, David. «The Indian in Mexican dramatic poetry (1823-1918)». Bulletin of Hispanic Studies, núm. 107 (1950), 163-171.

Yáñez, Agustín. «Concordancias indo-españolas». Abside, 37 (1973), 417-429.

Yepes Boscán, G. La novela indianista en Venezuela. Maracaibo: Universidad de Zulia, Facultad de Humanidades y Educación, 1965.

Yépez Miranda, Alfredo. «La novela indigenista». Revista de la Universidad [Cuzco], núm. 95 (1948), 3-35.

- «El paisaje y el indio en la literatura peruana». Revista Iberoamericana, núm. 21 (1946) 91-104.

Zayas de Lima, Perla J. «El indigenismo americano como doctrina literaria». Arbor, núm. 375 (1977), 95-102.

Zea, Leopoldo. «Negritud e indigenismo». Cuadernos Americanos, núm. 198 (1974), 116-130.

Zubritzki, Y. "De la 'Protección de los indios' del Padre de las Casas al indigenismo contemporáneo». Historia y sociedad, 5 (1966), 53-65.

Zum Felde, Alberto. "La tragedia del indio en Sudamérica». Cuadernos Americanos, núm. 9 (1943), 129-141.

Alegría, Ciro:

Obras:

Novelas completas. Arturo del Hoyo, comp. Madrid: Aguilar, 1959, etc.

La serpiente de oro. Santiago, Chile: Nascimento, 1935, etc.

Los perros hambrientos. Santiago de Chile: Zig-Zag, 1938, etc.

El mundo es ancho y ajeno. Santiago, Chile: Ercilla, 1941, etc. 
Bibliografias:

«Bibliografía de Ciro Alegría». Anuario Bibliográfico Peruano, 1967-1969, pp. 538-575.

"Ciro Alegría: pequeña nota biobibliográfica». Revista Peruana de Cultura, núms. 11-12 (1967), 70-71.

Rodríguez-Florido, Jorge J. «Bibliografía de y sobre Ciro Alegría». Chasqui, 4, 3 (1975), 23-54.

Estudios monográficos y disertaciones:

Alvarez de Toledo, Manuel H. Religión y superstición, en El mundo es ancho y ajeno. México, D. F.: Buena Prensa, 1963.

Bonneville, Henry. De l'indianisme à l'indigenisme: le romancier péruvien Ciro Alegría. Disertación doctoral inédita, La Sorbonne, 1950.

Bunte, Hans. Ciro Alegría y su obra dentro de la evolución literaria hispanoamericana. Lima: Librería Editorial Juan Mejía Baca, 1961.

Casado Linarejos, María del Carmen. La sociedad peruana de Ciro Alegría. Madrid: Universidad de Madrid, Facultad de Filosofía y Letras, 1974.

Collantes de Terán, Juan. El arte de novelar de Ciro Alegría. Disertación inédita, Universidad de Madrid, 1958.

D'Onofrio, Mario Leonardo. "La construcción de la narrativa indigenista andina: Ciro Alegría». Dissertation Abstracts International, 30 (1979), 4296 A-4297 A.

Early, Catherine E. «The narrative art of Ciro Alegría». Dissertation $A b$ stracts International, 33 (1973), 6906 A.

Escobar, Alberto. Ciro Alegrias «Serpiente de oro» interpretiert und sprachwissenschaflich untersucht. München: Ludwig-Maximillians Universität, 1959. Véase también Ciro Alegría y «La serpiente de oro». Lima: Juan Mejía Baca, 1959.

Ferreira, João Francisco. $O$ índio no romance de Ciro Alegría. Porto Alegre: Universitária, 1957.

Lapshina, Liubov’ N. La proyección social de la novela «El mundo es ancho y ajeno». Trujillo, Perú, 1971.

Pérez de Colosia Rodríguez, María Isabel. El indigenismo de la novela de Ciro Alegría. Disertación doctoral inédita, Universidad Complutense de Madrid, Curso 1971-1972.

Rodríguez-Florido, Jorge J. "Ciro Alegría: el hombre. Temas y aspectos estilísticos de su prosa narrativa». Dissertation Abstracts International, 36 (1975), 3743 A-3744 A. También como El lenguaje en la obra literaria. Medellín: Bedout, 1977.

Simposio Nacional sobre la Obra Narrativa de Ciro Alegría. La obra de Ciro Alegría. Arequipa: Universidad Nacional de Arequipa, 198?

Točilovac, Goran. La comunidad indígena y Ciro Alegría: un estudio de «El mundo es ancho y ajeno». Lima: Biblioteca Universitaria, 1975. 
Varona, Dora, comp. Ciro Alegría: trayectoria y mensaje. Lima: Varona, 1972.

Vilariño de Olivieri, Matilde. Las novelas de Ciro Alegría. Santander: Bedía, 1956.

Artículos críticos:

Alcock, Joe. «Lo elemental en El mundo es ancho y ajeno». Mercurio Peruano, núm. 395 (1959), 190-193.

Aldrich, Earl M., Jr. "Ciro Alegría and José María Arguedas, pivotal figures». En su The Modern Short Story in Peru (Madison: University of Wisconsin Press, 1966), pp. 114-140.

Alegría, Ciro: «Novela de mis novelas». Sphinx, 2, 3 (1938), 105-110. También Lima: Lumen, 1938.

Barck, C. «Probleme des Realismus in den Romanen Ciro Alegrías». Lateinamerik, núm. 19 (Primavera 1970), 53-66.

Bonneville, Henry. «Du métissage cultural à une culture métisse. Réflexions autour d'une thèse». Caravelle, núm. 8 (1967), 55-64.

- - "L'indigenisme littéraire andin. I: De l'indianisme à l'indigenisme. II: Le romancier péruvien Ciro Alegría». Les langues néo-latines, números 200-201 (1972), 1-58.

- - «El mestizaje y Ciro Alegría». En Instituto Internacional de Literatura Iberoamericana, Literatura de la emancipación hispanoamericana y otros ensayos (Lima: Universidad de San Marcos, 1972), pp. 206-210.

- . «Mort et résurrection de Ciro Alegría». Bulletin Hispanique, 70 (1968), 122-133.

Budor, Karl. "Aspectos de la picaresca canina en Cervantes y en Ciro Alegría». En La picaresca: orígenes, textos y estructuras (Madrid: Fundación Universitaria Española, 1979), pp. 1075-1094.

Bumpass, Faye L.: «Ciro Alegría, interpreter of the Peruvian Indian». En Homage to Charles Blaise Qualia (Lubbock: Texas Tech Press, 1962), pp. 139-145.

Callan, Richard J. «The artistic personality of Demetrio Sumallacta». Hispania, 45 (1962) 419-421.

Collantes de Terán, Juan. "Teoría y esquema en las narraciones de Ciro Alegría». Estudios Americanos, núms. 90-91 (1959), 119-140.

Cornejo Polar, Antonio. «La estructura del acontecimiento en Los perros hambrientos». Letras, núms. $78-79$ (1967), 5-25. También en su La novela peruana (Lima: Horizonte, 1977), pp. 65-84. También Lima: Universidad Nacional Mayor de San Marcos, Facultad de Letras y Ciencias Humanas, Instituto de Literatura, 1968.

- - «La imagen del mundo en La serpiente de oro». Revista de Crítica Literaria Latinoamericana, núm. 2 (1975), 51-62. También en su La novela peruana (Lima: Horizonte, 1977), pp. 49-64. 
Endres, Valerie. «The role of animals in El mundo es ancho y ajeno». Hispania, 48 (1965), 67-69.

Escajadillo, Tomás Gustavo. «Filiación y derrotero del último alcalde de Rumi». Revista de Crítica Literaria Latinoamericana, núm. 12 (1980), 225-253.

Escobar, Alberto. «La serpiente de oro o el río de la vida». En su Patio de letras (Lima: Caballo de Troya, 1965), pp. 180-257.

Galaos, José Antonio. «La tierra y el indio en la obra de Ciro Alegría». Cuadernos Hispanoamericanos, núm. 144 (1961), 387-395.

García, Antonio. "La novela del indio y su valor social». Revista de Indias, núm. 36 (1941), 26-39.

"Homenaje a Ciro Alegría y a Rubén Darío». Revista Peruana de Cultura, núms. 11-12 (1967), 43-146.

Josef, Bella. "Dimensión temporal en El mundo es ancho y ajeno de Ciro Alegría». En Libro de homenaje a Luis Alberto Sánchez (Lima: Universidad Nacional Mayor de San Marcos, 1967), pp. 249-257.

Lazo, Raimundo. «Ciro Alegría». En su La novela andina (México, D. F.: Porrúa, 1971), pp. 57-69.

López, Julio César. "Nota sobre el sentido de la vida en La serpiente de oro, novela de Ciro Alegría». En su Temas y estilos en ocho escritores (San Juan, P. R., 1967), pp. 31-36.

- El tema de la tierra en Ciro Alegría (la tierra como destino en la novela El mundo es ancho y ajeno)». En su Temas y estilos en ocho escritores San Juan, P. R.: 1967), pp. 9-29.

Lorenz, Günter W. «Ciro Alegría». En su Dialog mit Lateinamerika (Tübingen: Horst Erdmann, 1970), pp. 317-349. Traducido como Diálogo con América latina (Santiago de Chile: Pomaire, 1972), pp. 213-234.

Losada Guido, Alejandro. "Ciro Alegría como fundador de la realidad hispanoamericana». Acta litteraria Academiae Scientiarum Hungaricae, 17 (1975), 71-92.

McGourn, Francis T. «The priest in El mundo es ancho y ajeno». Romance Notes, 9 (1968), 224-233.

Mate, Hubert E. «Social aspects of novels by López y Fuentes and Ciro Alegría». Hispania, 39 (1956), 287-292.

Neves, Eugenia. "Dos clases antagónicas en pugna en El mundo es ancho y ajeno». Islas, núm. 13 (1963), 91-123. También «Clases antagónicas en El mundo es ancho y ajeno (de Ciro Alegría)». Idea, núms. $58-59$ (1964), $1,4,6,8$.

Oliver Belmas, Antonio. «Elementos folklóricos hispánicos en El mundo es ancho y ajeno, de Ciro Alegría». En su La natividad en los Premios Nobel de Hispanoamérica y otros ensayos (Madrid: Cultura Hispánica, 1969), pp. 123-128.

Ospina Londoño, Uriel. «Rastignac y Rosendo Maqui». En su Problemas y perspectivas de la novela americana (Bogotá: Tercer Mundo, 1964), pp. 175-199. 
Pérez de Colosia Rodríguez, María Isabel. «El indigenismo y las novelas de Ciro Alegría». Anales de Literatura Hispanoamericana, núm. 5 (1976), 165-193.

Rodríguez-Luis, Julio. "Ciro Alegría». En su Hermenéutica y praxis del indigenismo (México, D. F.: Fondo de Cultura Económica, 1980), pp. 111-121.

Rodríguez Monegal, Emir. «Hipótesis sobre Ciro Alegría». Mundo Nuevo, núm. 11 (1967), 48-51. También en su Narradores de esta América, 2. ${ }^{a}$ ed. (Montevideo: Alfa, 1969-1974), I, 166-174.

Rodríguez Peralta, Phyllis. «Ciro Alegría: culmination of indigenist-realism in Perú». Journal of Spanish Studies: Twentieth Century, 7 (1979), 337352.

Ruiz Silva, José C. «¿Sigue teniendo vigencia el problema del indio? (en torno a Ciro Alegría)». Cuadernos Hispanoamericanos, núms. 314-315 (1976), 616-623.

Sanguinetti de Ferrero, Gracia. «Presencia de la tierra en El mundo es ancho $y$ ajeno». En La naturaleza y el hombre en la novela hispanoamericana (Antofagasta: Universidad del Norte, 1969), pp. 123-144.

Schiro, Roberto. «Los perros hambrientos de Ciro Alegría». Universidad [Santa Fe], núm. 75 (1968), 95-124.

Siebenmann, Gustav. «La serpiente de oro: novela cholista». Anales de Literatura Hispanoamericana, núm. 9 (1980), 255-272.

Sparks, Enrique Normand. "Una observación sobre Los perros hambrientos (los relatos interiores)». Mercurio Peruano, núm. 335 (1955), 128-135.

Spell, Jefferson Rea. "Ciro Alegría, "criollista" of Peru». En su Contemporary Spanish American Fiction (Chapel Hill, N. C.: University of North Carolina Press, 1944), pp. 253-268.

Tamayo Vargas, Augusto. «Ciro Alegría, José María Arguedas y la generación del 30». En Instituto Internacional de Literatura Iberoamericana, La novela iberoamericana contemporánea (Caracas: Universidad Central de Venezuela, Organización de Bienestar Estudiantil, 1966), pp. 125-136.

—. «Los tres ases de la baraja narrativa de Ciro Alegría». Alpha, 2, 7 (1966), 7-11. También en su 150 artículos sobre el Perú (Lima: Universidad Nacional Mayor de San Marcos, Facultad de Ciencias Humanas, Instituto de Letras, 1966), pp. 554-558.

Terlingen, J. «Espíritu del Perú en una novela de Ciro Alegría». Indianoromania, núm. 1 (1962), 9-18.

Urdanivia Bertarelli, Eduardo. «Para una nueva lectura de Ciro Alegría». Revista de Crítica Literaria Latinoamericana, núms. 7-8 (1978), 175-181.

Vázquez Amaral, José. «Ciro Alegría: Broad and alien is the world-the Indian in literature». En su The contemporary Latin American Narrative (New York: Las Américas, 1970), pp. 64-80. 
Arguedas, Alcides:

Obras:

Obras completas. México, D. F.: Aguilar, 1959-1960.

Pueblo enfermo; contribución a la psicología de los pueblos hispanoamericanos. Buenos Aires: Vda. de Luis Tasso, 1909, etc.

Raza de bronce. La Paz: González y Medina, 1919, etc.

Estudios monográficos y disertaciones:

Alcázar, Moisés. Alcides Arguedas, etapas de la vida de un escritor. La Paz: Talleres Gráficos Bolivianos, 1963.

Plevich, Mary. "Alcides Arguedas: contemporary Bolivian writer». Dissertation Abstracts International, 18 (1957), 1557-1558.

Reinaga, Fausto. Alcides Arguedas. La Paz: Talleres Gráficos Gutemberg, 1960.

Vilela, Hugo. Alcides Arguedas y otros nombres en la literatura de Bolivia. Buenos Aires: Kier, 1945.

Ensayos criticos:

Bellini, Giuseppe. "Alcides Arguedas en la novela moderna». Revista Hispánica Moderna, 26 (1960), 133-135.

Brotherston, Gordon. "Alcides Arguedas as a 'defender of Indians' in the first and later editions of Raza de bronce». Romance Notes, 13 (1971), 41-47.

Carrión, Benjamín. «Alcides Arguedas». En su Los creadores de la nueva América (Madrid: Sociedad General Española de Librería, 1928), pp. 165217.

Columba Rocabado, Margarita. «E1 indio y la mujer en la novela de Alcides Arguedas». Revista de Cultura, 2, 2 (1956), 234-306.

Fernández, Teodosio. «El pensamiento de A. Arguedas y la problemática del indio: para una revisión de la novela indigenista». Anales de Literatura Hispanoamericana, núm. 9 (1980), 49-64.

Ford, Richard. «La estampa incaica intercalada en Raza de bronce». Romance Notes, 18 (1978), 311-317.

Ghiano, Juan Carlos. «La raza de bronce de Alcides Arguedas». Cursos y Conferencias, núm. 172 (1946), 266-269.

Júlio, Sylvio. «Os índios bolivianos num romance de Alcides Arguedas». En su Idéas e combates (Rio de Janeiro: Revista de Língua Portuguesa, 1927), pp. 203-212.

Lacosta, Francisco C. «E1 indigenismo literario de Alcides Arguedas». Cultura Boliviana, 2 (1965), 4-5, 18. 
Lastra, Pedro. «Sobre Alcides Arguedas». Revista de Crítica Literaria Latinoamericana, núm. 12 (1980), 213-223.

Lijerón Alberdi, Hugo. «Raza de bronce». Hispania, 46 (1963), 530-532.

Marof, Tristán. «Proceso de un escritor: Alcides Arguedas». En su La verdad socialista en Bolivia (La Paz, 1938), pp. 73-88.

Medinaceli, Carlos. «La imaginación y la envidia en Pueblo enfermo». Universidad de Potosí, núm. 28 (1949), 81-89.

- «La inactualidad de Arguedas». Universidad de Potosí, núm. 28 (1949), 74-80.

Mitre, Antonio F. «Alcides Arguedas y la conciencia nacional». Nova Americana, núm. 3 (1980), 85-99.

Moretic, Yerko. «Raza de bronce». Atenea, núm. 304 (1950), 131-140.

Ostria González, Mauricio. "Atisbos estéticos y estilísticos en Raza de bronce». Anales de la Universidad del Norte, núm. 6 (1967), 29-89.

Otero, Gustavo A. «Temperamento, cultura y obra de Alcides Arguedas». Casa de la Cultura Ecuatoriana, 2, 4 (1947), 164-193.

- _- «Alcides Arguedas». En su Figuras de la cultura boliviana (Quito: Casa de la Cultura Ecuatoriana, 1952), pp. 323-353.

Plevich, Mary. «El origen del arguedismo». Universidad de Antioquí, número $134(1958)$, 407-413.

Rodríguez-Luis, Julio. «Alcides Arguedas». En su Hermenéutica y praxis del indigenismo (México, D. F.: Fondo de Cultura Económica, 1980), pp. 56-87.

Salamanca Lafuente, Rodolfo. "Vigencia del arguedismo en Bolivia». Kollasuyo, núm. 65 (1947), 42-51.

Sánchez, Luis Alberto. «Alcides Arguedas». En su Escritores representativos de América, 2. ${ }^{\mathrm{a}}$ serie (Madrid: Gredos, 1964), II, 92-106.

Arguedas, José María:

Obras:

Los ríos profundos. Buenos Aires: Losada, 1958, etc.

Todas las sangres. Buenos Aires: Losada, 1964, etc.

Yawar fiesta. Lima: Cía. de Impresiones y Publicidad, 1941, etc.

El zorro de arriba y el zorro de abajo. Buenos Aires: Losada, 1970, etc.

\section{Bibliografias:}

«Biobibliografía de José María Arguedas Altamirano». Anuario bibliográfico peruano, 1967-1969, pp. 596-633.

Rowe, William. "Contribución a una bibliografía de José María Arguedas». Revista Peruana de Cultura, núms. 13-14 (1970), 179-197. 
Estudios monográficos y disertaciones:

Arroyo Posadas, Moisés. José María Arguedas: etapas de su vida. Abancay: «Amamkay», 1939. También 1972.

_- La multitud y el paisaje peruano en los retratos de José María Arguedas. Lima: Enrique Bustamante y Ballaivián, 1939.

Bourricaud, François. El tema de la violencia en 'Yawar fiesta'. Montevideo: Universidad de la República, Departamento de Literatura Hispanoamericana, 1970. También en Études latino-américaines, 2 (1964) 111-128. También como «Le thème de la violence dans Yawar fiesta». Annales de la Faculté des Lettres et Sciences de l'Université de Strasbourg, 38, 2 (1964), 115-132.

Cornejo Polar, Antonio. Los universos narrativos de José María Arguedas. Buenos Aires: Losada, 1973.

Domínguez, Néstor de Jesús. «El indio de José María Arguedas. Su ilación con la naturaleza y el universo humano». Dissertation Abstracts International 38 (1977), 3533A.

Flores V., Julio, comp. José María Arguedas y la nueva novela indígena del Perú. Valparaíso, Chile: Revista «Coral», 1970.

Gerhards, Ernest. Das Bild des Indio in der peruanischer Literatur. Mythos und Mystifikation der indianischen Welt bei José María Arguedas. Berlin: Freie Universität Berlin, Fachbereich Neuer Fremdsprachliche Philologien, 1972.

Klarén, Sara Castro. El mundo mágico de José María Arguedas. Lima: Instituto de Estudios Peruanos, 1973.

Levano, César. Arguedas, un sentimiento trágico de la vida. Lima: J. Mejía Baca, 1969.

Marín, Gladys C. La experiencia americana de José María Arguedas. Buenos Aires: Fernando García Cambeiro, 1973.

Morales, J. V. «Die Überwindung des literarischen Indigenismo in Los ríos profundos von José María Arguedas». Dissertation Abstracts International, 38 (1978), 4643C.

Muñoz, Silverio. José María Arguedas y el mito de la salvación por la cultura. Minneapolis: University of Minnesota, Instituto para el Estudio de Ideologías y Literatura, 1980.

Pantigoso, Edgardo J. La rebelión contra el indigenismo y la afirmación del pueblo en el mundo de José María Arguedas. Lima: Juan Mejía Baca, 1981.

Ratliff, William F. «Cultures in conflict: the historical, mythic, and legendary dimensions of the narrative works of José María Arguedas and Miguel Angel Asturias». Dissertation Abstracts International, 41 (1981), 3127A.

Recopilación de textos sobre José María Arguedas. La Habana: Casa de las Américas, 1976.

Rowe, William. Mito e ideología en la obra de José María Arguedas. Lima: Instituto Nacional de Cultura, 1979. 
Urello, Antonio. José María Arguedas: el nuevo rostro del indio, una estructura mítico-poética. Lima: Juan Mejía Baca, 1974.

Vargas Llosa, Mario: José María Arguedas entre sapos y halcones. Madrid: Cultura Hispánica del Centro Iberoamericano de Cooperación, 1978. También en Boletín de la Academia Peruana de la Lengua, 12 (1978), 89-117.

\section{Artículos críticos:}

Aldrich, Earl M., Jr. «Ciro Alegría and José María Arguedas: pivotal figures». En su The modern short story in Peru (Madison: University of Wisconsin Press, 1966), pp. 114-140.

—. «The Quechua world of José María Arguedas». Hispania, 45 (1962), 62-66.

Barrenechea, Ana María. «Escritor, escritura y 'materia de las cosas' en los Zorros de Arguedas». En su Textos hispanoamericanos (Caracas: Monte Avila, 1978), pp. 289-318.

Bellini, Giuseppe. "I miti della memoria ne Los ríos profundos». En su Il laberinto magico (Milano: Cisalpino-Goliardica, 1973), pp. 87-118.

Brotherston, Gordon. «Tupac Amaru dismembered: José María Arguedas». En su The emergence of the Latin American novel (Cambridge: Cambridge University Press, 1977), pp. 98-109.

Cornejo Polar, Antonio. «José María Arguedas: las nuevas dimensiones del indigenismo». Insula, núms. 332-333 (1974), 11, 22.

- "José María Arguedas, revelador de una realidad cambiante». Nueva Narrativa Hispanoamericana, 2, 2 (1972) 179-185. También en Instituto Internacional de Literatura Iberoamericana, La literatura de la emancipación hispanoamericana y otros ensayos (Lima: Universidad de San Marcos, 1972), pp. 211-216.

- - "Nota sobre la función del espacio en Los rios profundos». Anales de Literaura Hispanoamericana, núms. 2-3 (1973-1974), 649-655.

—. "Los ríos profundos: un universo compacto y quebrado». En su La novela peruana (Lima: Horizonte, 1977), pp. 85-137.

—_. «El sentido de la narrativa de Arguedas». Revista Peruana de Cultura, núms. 13-14 (1970), 17-48.

- - «El zorro de arriba y el zorro de abajo: función y riesgo del realismo». En Memorias del IV Congreso de la Nueva Narrativa Hispanoamericana (Lima: Horizonte, 1977), pp. 139-144.

Delgado, Wáshington. "Jorge Icaza y José María Arguedas. Problemas conceptuales y artísticos del indigenismo literario». América Indígena, 30 (1970), 183-190.

Di Carlo, Erica Gay. "Arguedas: l'indigenismo e la scrittura». Annali, Istituto Universitario, Napoli; Sezione Romanza, 21 (1979), 235-265.

Dorfman, Ariel. "José María Arguedas y Mario Vargas Llosa: dos visiones de una sola América». Casa de las Américas, núm. 64 (1971), 6-19. También en su Imaginación y violencia en América (Santiago de Chile: Universi- 
taria, 1970), pp. 193-223. También en Helmy F. Giacoman y José Miguel Oviedo, comps. Homenaje a Mario Vargas Llosa (Long Island City, NY: Las Américas, 1972), pp. 135-160. Originalmente como "Arguedas y la epopeya americana». Amaru, núm. 11 (1969), 18-26.

- «Puentes y padres en el infierno: Los ríos profundos». Revista de Crítica Literaria Latinoamericana, núm. 12 (1980), 91-137.

Escajadillo, Tomás Gustavo. «Tópicos y símbolos religiosos en el primer capítulo de Los ríos profundos». En Actas del Simposio Internacional de Estudios Hispánicos (Budapest: Akadémiai Kiadó, 1978), pp. 383-393. También en Revista de Crítica Literaria Latinoamericana, núm. 9 (1979), 57-68.

Escobar, Alberto. "La guerra silenciosa de Todas las sangres». Revisia Peruana de Cultura, núm. 5 (1965), 37-49. También en su Patio de letras (Caracas: Monte Avila, 1971), pp. 365-381.

- - «José María Arguedas: el desmitificador del indio y del rito indigenista». Nova Americana, núm. 3 (1980), 141-196.

Fell, Eva-Marie. «La société andine dans Los ríos profundos». Les langues néo-latines, núm. 205 (1973), 23-40.

Flores, Julio. "José María Arguedas: una experiencia sin paralelo». Humboldt, núm. 68 (1979), 46-48.

Forgues, Roland. «Todas las sangres de José María Arguedas, un testimonio literario y un afán totalizantae». En su La sangre en llamas (Lima: Studium, 1979), pp. 7-38.

- - "Todas las sangres (o el relato de un proceso de cambio socioeconómico y sociocultural en la sierra peruana)». Cuadernos Hispanoamericanos, núm. 300 (1975), 659-674. También como «Las estructuras socioeconómicas de la explotación de la tierra en la sierra peruana, según Todas las sangres, de José María Arguedas». Letras de Deusto, 7, 13 (1977), $159-160$.

Gómez, Clara Luz. "Visión de la naturaleza en Todas las sangres, de José María Arguedas». En Estudios de Critica Literaria (La Plata: Universidad Nacional de La Plata, Facultad de Humanidades y Ciencias de la Educación, 1973), pp. 105-119.

Gutiérrez, Miguel. «Estructura e ideología de Todas las sangres». Revista de Crítica Literaria Latinoamericana, núm. 12 (1980), 139-176.

Irish, J. A. George. «J. M. Arguedas and Peruvian neo-indigenismo». Revista/ Review interamericana, 10, 2 (1980), 173-187.

Jara Cuadre, René. "José María Arguedas y el indigenismo». Revista signos de Valparaíso, 3, 1-2 (1969), 133-138.

Jiménez, Reynaldo. «Realidad y mitificación: el narrador-niño en Los ríos profundos». Texto crítico, núm. 14 (1979), 104-116.

Klarén, Sara Castro. "Las fuentes del narrador en Los ríos profundos». Cuadernos Americanos, núm. 175 (1971), 230-238.

- «Todas las sangres: a change of skin». Latin American Literary Review, núm. 2 (1973), 83-98. 
«The word and the world in Arguedas». Review, núms. 25-26 (1980), 17-21.

Lienhard, Martín. «Cultura quechua campesina y espacios utópicos en la narrativa de José María Arguedas: acerca de la dominación cultural en Perú». Escritura, núm. 11 (1981), 173-183.

—. «Tradición oral y novela: los 'zorros' en la última novela de José María Arguedas». Revista de Crítica Literaria Latinoamericana, núm. 6 (1977), 81-92.

- -La última novela de Arguedas: imagen de un lector futuro». Revista de Crítica Literaria Latinoamericana, núm. 12 (1980), 177-196.

Losada Guido, Alejandro. "José María Arguedas: la creación como compromiso y la voluntad de realismo». En su Creación praxis (Lima: Universidad Nacional Mayor de San Marcos, Dirección de Bibliotecas y Publicaciones, 1976), pp. 39-67. Originalmente como «La obra de José María Arguedas y la sociedad andina. Interpretación de su creación literaria como praxis social». Eco, núm. 162 (1974), 592-620.

March, Kathleen N. «Lenguaje y lucha social en El zorro de arriba y el zorro de abajo, de José María Arguedas». Anales de Literatura Hispanoamericana, núm. 8 (1979), 145-167.

Merino de Zela, Mildred. «Vida y obra de José María Arguedas». Revista Peruana de Cultura, núms. 13-14 (1970), 127-178. También Lima, 1970?

Montoya, Rodrigo. «Yawar fiesta: una lectura antropológica». Revista de Crítica Literaria Latinoamericana, núm. 12 (1980), 55-68.

Moretič, Yerko. «José María Arguedas y la literatura peruana indigenista». Atenea, núm. 406 (1964), 205-216.

Muñoz, Silverio. "Yawar fiesta: el mito de la salvación por la cultura». Texto crítico, núm. 14 (1979), 71-103.

Paoli, Robert. "Técnica e ideología en Yawar fiesta». En Homenaje a Jorge Basadre (Lima: Pontificia Universidad Católica del Perú, 1978), II, 215235.

Rama, Angel. «Recuperación del pensamiento mítico en José María Arguedas». Latinoamérica, núm. 9 (1976), 248-274.

- - «Los ríos profundos del mito y de la historia». Revista de Crítica Literaria Latinoamericana, núm. 12 (1980), 69-90.

Rodríguez-Luis, Julio. «José María Arguedas». En su Hermenéutica y praxis del indigenismo (México, D. F.: Fondo de Cultura Económica, 1980), pp. 122-226.

Rowe, William. "Mito, lenguaje e ideología en Los ríos profundos». Textual, núm. 7 (1973), 2-12.

- "El nuevo lenguaje de Arguedas en El zorro de arriba y el zorro de abajo». Texto crítico, núm. 11 (1978), 198-212.

Vargas Llosa, Mario. «Tres notas sobre Arguedas». En Jorge Lafforgue, comp. Nueva novela latinoamericana (Buenos Aires: Paidós, 1969-1972), I, 30-54.

- - «Literatura y suicidio: el caso Arguedas (El zorro de arriba y el zorro de abajo)». Revista Iberoamericana, núms. 110-111 (1980), 3-28. 
«Seeing with the Indian's eyes». Review, núms. 25-26 (1980), 52-56.

. «La utopía arcaica». Revista de la Universidad de México, 327 (1978), $1-10$.

Asturias, Miguel Angel (1899-1974):

Obras:

Obras escogidas. Prólogo de José María Souvirón. Madrid: Aguilar, 1955, etc. Obras completas. Prólogo de José María Souvirón. Madrid: Aguilar, 1968.

Hombres de maíz. Buenos Aires: Editorial Losada, 1949, etc.

Bibliografías:

Andrea, Pedro F. de. «Miguel Angel Asturias, anticipo bibliográfico». Revista Iberoamericana, núm. 67 (1969), 133-269.

- - "Miguel Angel Asturias en México: ensayo bibliográfico». Boletín de la Comunidad Latinoamericana de Escritores, 2 (1968), 10-26. También México, D. F.: «Hojas Volantes» de la CLE, 1969.

Moore, Ernest Richard. «Miguel Angel Asturias: a bibliography». Boletín bibliográfico, 27 (1970), 85-90, 107-111.

Estudios monográficos y disertaciones:

Baker, Rilda Louise. «Narrative process and significance in Hombres de maiz and El obsceno pájaro de la noche [de José Donoso]». Dissertation Abstracts International, 37 (1976), 354A.

Bellini, Giuseppe. La narrativa di Miguel Angel Asturias. Milano: Istituto Editoriale Cisalpino, 1966. También como La narrativa de Miguel Angel Asturias. Buenos Aires: Editorial Losada, 1969.

Callan, Richard J. Miguel Angel Asturias. New York: Twayne, 1970.

Castelpoggi, Atilio Jorge. Miguel Angel Asturias. Buenos Aires: La Mandrágora, 1961.

Couffon, Claude. Miguel Angel Asturias: une étude. Paris: P. Seghers, 1970.

Essays on Miguel Angel Asturias. Milwaukee: University of Wisconsin, Latin American Center, 1972.

Giacoman, Helmy F., comp. Homenaje a Miguel Angel Asturias, variaciones interpretativas en torno a su obra. Long Island City, N. Y.: Anaya-Las Américas, 1972.

González del Valle, Luis, y Vicente Cabrera. La nueva ficción hispanoamericana a través de M. A. Asturias y G. García Márquez. New York: Eliseo Torres, 1972.

León Hill, Eladia. Miguel Angel Asturias, lo ancestral en su obra literaria. New York: Eliseo Torres, 1972. 
Lorenz, Günter W. Miguel Angel Asturias: Biographie, ausgewähte Gedichte, Abbildungen, Faksimile, Dokumente. Neuwied: Luchterhand, 1968.

- Miguel Angel Asturias: Porträt und Poesie. Neuwied: Hermann Luchterhand, 1963.

Pilón, Marta. Miguel Angel Asturias. Guatemala: Cultural Centroamericana, Librería Proa, 1968.

Prieto, René. «A semiotic analysis of Hombres de maiz by Miguel Angel Asturias». Dissertation Abstracts International, 41 (1980), 2136A.

Santizo Pedoglio, Mario José. «Un estudio lingüístico de Hombres de maiz». Dissertation Abstracts International, 36 (1975), 3662A-3663A.

Sierra Franco, Aurora. Miguel Angel Asturias en la literatura. Guatemala: Istmo, 1969.

Verdugo, Iber. El carácter de la literatura hispanoamericana y la novelística de Miguel Angel Asturias. Guatemala: Editorial Universitaria, 1968.

\section{Artículos críticos:}

Adams, Rolstan P. «The search for the indigenous: an evaluation of the literary vision of Alejo Carpentier and Miguel Angel Asturias». En The analysis of Hispanic texts: current trends in methodology (Jamaica: Bilingual Press/York College, 1976), pp. 74-88.

Alegría, Ciro. «Hombres de maiz de Miguel Angel Asturias». Asomante, 6, 2 (1950), 92-94.

Alvarado, Humberto. «La realidad guatemalteca en la obra de Asturias». Revista de Guatemala, 10, 2 (1960), 46-65.

Arango L., Manuel Antonio. «Aspectos sociales en las novelas de Miguel Angel Asturias». Cuadernos americanos, núm. 228 (1980), 179-199.

- -Correlación surrealista y social en dos novelas: El reino de este mundo, de Alejo Carpentier, y Hombres de maíz, de Miguel Angel Asturias». Explicación de textos literarios, 7 (1978), 23-30.

Armijo, Roberto. «El mito maya-quiché en Hombres de maiz». Universidad [El Salvador], 95, 2 (1970), 55-77.

Barbieri, Vicente. «Miguel Angel Asturias. Hombres de maíz». Sur, núm. 189 (1950), 89-93.

Bellini, Giuseppe. «Destrucción del personaje en las novelas de Asturias». Norte, 10, 4-5 (1969), 80-86. También como «La destrucción del personaje en las novelas de Miguel Angel Asturias». En Studi di letteratura ispanoamericana (Milano: Istituto Editoriale Cisalpino, 1967-71?), III, 7-15.

—. «Il laberinto magico di Miguel Angel Asturias». En Studi di letteratura ispano-americana (Milano: Istituto Editoriale Cisalpino, 1967-71?), III, 55-75.

Bernu, Michèle. «Mythe et société dans Hombres de maíz de Miguel Angel Asturias». Caravelle, núm. 29 (1977), 45-64.

Bertino, Cledy M. «Miguel Angel Asturias y el simbolismo mítico de Hombres de maíz». Universidad [Santa Fe], núm. 68 (1966), 233-266. 
Brotherston, Gordon. «La mágica selva americana: Miguel Angel Asturias [Hombres de maíz]". Escritura, núms. 5-6 (1978), 79-97.

- . The presence of Mayan literature in Hombres de maiz and other works by Miguel Angel Asturias». Hispania, 58 (1975), 68-74.

Callan, Richard J. "The quest for myth in Miguel Angel Asturias' Hombres de maíz». Hispanic Review, 36 (1968), 249-261.

Christ, Ronald. "The text as translation [Hombres de maiz]". Review, 15 (1975), 28-33.

Coleman, Alexander. «A reader's confession [Hombres de maíz]». Review, 15 (1975), 23-27.

Conte, Rafael. «Miguel Angel Asturias o el lenguaje». En su Lenguaje y violencia (Madrid: Al-Borak, 1972), pp. 99-105.

Corvalán, Octavio: «Hombres de maíz: una novela mito». Journal of Spanish studies: twentieth century, 7 (1979), 33-40.

Donahue, Francis James. «Asturias: perfil literario». Cuadernos Americanos, núm. 165 (1969), 145-165.

—. «Miguel Angel Asturias: su trayectoria literaria». Cuadernos Hispanoamericanos, núm. 186 (1965), 507-527.

Dorfman, Ariel. «Hombres de maiz: el mito como tiempo y palabra». Aienea, núm. 167 (1968), 129-153. También en su La violencia en América (Santiago de Chile: Editorial Universitaria, 1970), pp. 65-92. También como «Myth as time and word». Review, núm. 15 (1975), 12-22.

Estrada, Ricardo H. «Estilo y magia del Popol-Vuh en Hombres de maíz». Humanidades (Guatemala), 3, 2 (1961), 1-15.

Europe, núms. 553-554 (1975).

Fernández Font, Jorge. «Apuntes para una lectura social de dos novelas de Miguel Angel Asturias [Hombres de maiz y El señor presidente]». Revista Mexicana de Sociología, 41 (1979), 863-879.

Galaos, José Antonio. «Los dos ejes de la novelística de Miguel Angel Asturias». Cuadernos Hispanoamericanos, núm. 154 (1962), 126-139.

Gennaro, Giuseppe de. «Il sentimento tragico della vita nell'opera di M. A. Asturias». Letture, 5 (1968), 1-10.

Harss, Luis. «Miguel Angel Asturias». En su Los nuestros (Buenos Aires: Editorial Sudamericana, 1966), pp. 87-127. También con Barbara Dohmann como "Miguel Angel Asturias, or the land where the flowers bloom». En su Into the mainstream (New York: Harper and Row, 1961), pp. 68101.

«Homenaje a Miguel Angel Asturias». Cultura, núm. 46 (1967).

«Homenaje a Miguel Angel Asturias». Humanidades (Guatemala), 18, 2 (1960).

Leal, Luis. "Myth and social realism in Miguel Angel Asturias». Comparative Literature Studies, 5 (1968), 237-247.

Leiva, Raúl. «Miguel Angel Asturias». Casa de las Américas, núm. 8 (1961), 61-69. También en su Iluminaciones, crítica literaria (México, D. F.: Editorial Letras, 1973), pp. 217-241. 
Lorand de Olazagasti, Adelaida. «Miguel Angel Asturias y su narrativa guatemalteca». En su $E l$ indio en la narrativa guatemalteca (San Juan, P. R.: Editorial Universitaria, 1968), pp. 85-121.

Lorenz, Günter W. «Diálogo con Miguel Angel Asturias». Mundo Nuevo, núm. 43 (1970), 35-52. También en su Diálogo con América Latina (Santiago de Chile: Editorial Pomaire, 1972), pp. 235-269.

Martin, Gerald M. «Emir Rodríguez Monegal y 'Los dos Asturias'». Revista Iberoamericana, núm. 69 (1969), 505-516.

- «Pattern for a novel: an analysis of the opening of Hombres de maiz». Revista de Estudios Hispánicos, 5 (1971), 223-241.

—. «Theme and structure in Asturias' Hombres de maíz». Modern Language Quarterly, 30 (1969), 582-602.

Meléndez, Concha. «El mito viviente en Hombres de maiz». Asomante, 24, 3 (1969), 30-47.

Méndez, Francisco. «Fama, palabra y magia de Miguel Angel Asturias». Revista de Guatemala, 18, 2 (1960), 18-45. También Salon 13, 1, 4 (1960), 99-119.

Menton, Seymour. «Miguel Angel Asturias: realidad y fantasía». En su Historia critica de la novela guatemalteca (Guatemala: Editorial Univeristaria, 1960), pp. 195-241.

Rodríguez Monegal, Emir. «Los dos Asturias». Revista Iberoamericana, número 67 (1969), 13-20. También en su Narradores de esta América, 2. ${ }^{a}$ ed. (Montevideo: Editorial Alfa, 1969-74), I, 177-186.

Rogman, Horst. «Miguel Angel Asturias, dios maya». Escritura, núms. 5-6 (1978), 11-24.

Salomon, Noel. «Le monde magique de Miguel Angel Asturias». Acta litteraria Academiae Scientiarum Hungaricae, 11 (1969), 223-236.

Sandoval de Fonseca, Virginia. «Hombres de maíz, trascendentalización de la existencia». Revista de Filología y Lingüistica de la Universidad de Costa Rica, 1, 1 (1975), 3-6.

- «Introducción a la lectura de Hombres de maiz». Repertorio latinoamericano, 1, 4 (1975), 10-14.

Santizo, Mario. «La unidad estructural y temática de Hombres de maiz». Anales de Literatura Hispanoamericana, núm. 4 (1975), 115-131.

Segala, Amos. «I miti dimistificanti di Asturias». Dramma, 45, 7 (1969), 36-45. También en Studi di letteratura ispano-americana (Milano: Istituto Editoriale Cisalpino, 1967-71?), III, 33-37.

Senghor, Léopoldo Sédar. "Asturias el mestizo». Sin nombre, 6, 3 (1976), 67-73. También como «Asturias le métis». Studi di letteratura ispanoamericana, 7 (1976), 33-41.

Vargas Llosa, Mario. «Una nueva lectura de Hombres de maíz». Eco, núm. 210 (1979), 637-644.

Verdevoye, Paul. «Miguel Angel Asturias y la 'nueva novela'». Revista Iberoamericana, núm. 67 (1969), 21-29. 
Wilson, Diana Armas. «The dynamics of myth and legend: Miguel Angel Asturias' Men of maize». Denver Quarterly, 11, 4 (1977), 177-184.

Zuleta Alvarez, Enrique. «El realismo poético de Miguel Angel Asturias». Norte, 6, 5 (1965), 107-111.

Castellanos, Rosario:

Obras:

Balún-Canán. México, D. F.: Joaquín Mortiz, 1957.

Oficio de tinieblas. México, D. F.: Joaquín Mortiz, 1962.

\section{Bibliografias:}

Ahern, Maureen. «A critical bibliography of and about the works of Rosario Castellanos». En Homenaje a Castellanos, q. v., pp. 121-174.

Monografias y disertaciones:

Dybvig, Rhoda. Rosario Castellanos; biografía y novelística. México, D. F.: Ediciones de Andrea, 1965.

Félix, Lourdes Carrasco de. «La función del mito en la narrativa de Rosario Castellanos». Dissertation Abstracts International, 40 (1980), 3995A.

Homenaje a Rosario Castellanos. Valencia: Albatros/Hispanófila, 1980.

Reyes Nevares, Beatriz. Rosario Castellanos. México, D. F.: Secretaría de la Presidencia, Departamento Editorial, 1976.

Artículos críticos:

Benedetti, Mario. «Rosario Castellanos y la incomunicación racial». En su Letras del continente mestizo, 2. ${ }^{a}$ ed. (Montevideo: Arca, 1969), pp. 165170. Orig. 1967.

Campos, Jorge. «Novelas e ideas de Rosario Castellanos». Insula, núm. 211 (1964), 11.

Carballo, Emmanuel. «Rosario Castellanos». En su Diecinueve protagonistas de la literatura mexicana del siglo XX (México, D. F.: Empresas Editoriales, 1965), pp. 409-424.

Castro, Dolores. «[Balún-Canán]». La palabra y el hombre, núm. 7 (1958), 33-36.

Cosse, Rómulo. «El mundo creado en Oficio de tinieblas de Rosario Castellanos». Latino América, 13 (1980), 83-113.

Fox-Lockert, Lucía. «Rosario Castellanos: Balún-Canán». En su Women novelists in Spain and Spanish America (Metuchen, N. J.: Scarecrow Press, 1979), pp. 202-215. 
García-Barragán, María Guadalupe. «Rosario Castellanos en la novela y el cuento indigenistas». Proceedings of the Pacific Northwest Conference on Foreign Languages, 20 (1969), 113-120.

González, Alfonso. "Lenguaje y protesta en Oficio de tinieblas». Revista de Estudios Hispánicos, 9 (1975), 441-450.

Gruber, Vivian M. «The general and the lady: two examples of religious persecution in the Mexican novel». En Lyle C. Brown y William F. Cooper, comps. Religion in Latin American life and literature (Waco, Tex.: Markahm Press Fund, Baylor University Press, 1980), pp. 212-219.

Leiva, Raúl. «Oficio de tinieblas». Nivel, núm. 48 (1962), 3.

Lorenz, Günter. «Rosario Castellanos». En su Diálogo con América Latina (Santiago de Chile: Pomaire, 1972), pp. 185-211.

Millán, María del Carmen. «En torno a Oficio de tinieblas». Anuario de Letras, 3 (1963), 287-299.

Passafari de Gutiérrez, Clara. «Rosario Castellanos y 'El ciclo de Chiapas'». En su Los cambios en la concepción y estructura de la narrativa mexicana desde 1947 (Rosario: Universidad Nacional del Litoral, Facultad de Filosofía, 1968), pp. 171-187.

Rodríguez Chicharro, César. «Rosario Castellanos: Balún-Canán». La palabra $y$ el hombre, núm. 9 (1959), 61-67.

«Rosario Castellanos». En Los narradores ante el público (México, D. F.: Joaquín Mortiz, 1966-67), I, 87-98.

Rosser, Harry L. "The structure and psyche of provincial society in transition: Magdaleno, Fuentes, Galindo, Castellanos». En su Conflict and transition in rural Mexico (Boston: Croissroads Press, 1980), pp. 119-160.

Selva, Mauricio de la. «[Balún-Canán]». Cuadernos Americanos, núm. 97 (1958), 272-273.

Sommers, Joseph. «Forma e ideología en Oficio de tinieblas de Rosario Castellanos». Revista de Crítica Literaria Latinoamericana, núms. 7-8 (1978), 73-91.

- «Rosario Castellanos: nuevo enfoque del indio mexicano». La palabra y el hombre, núm. 29 (1964), 83-88.

Speratti Piñero, Emma Susana. «[Balún-Canán]». Revista de la Universidad de México, 12, 5 (1958), 30.

ICAZA, JORGE:

Obras:

Obras escogidas. México, D. F.: Aguilar, 1961.

Cholos. Quito, 1935, etc.

El chulla Romero y Flores. Quito: Rumiñahui, 1959, etc.

Huairapamushcas. Quito: Casa de la Cultura Ecuatoriana, 1948.

Huasipungo. Quito: Nacional, 1934, etc. 
Estudios monográficos y disertaciones:

Baxter, Edwin Smith. «Reevaluation of Jorge Icaza's Huasipungo». Dissertation Abstracts International, 40 (1979), 2084 A.

Cueva, Agustín. Jorge Icaza. Buenos Aires: Centro Editor de América Latina, $1969, \mathrm{c} 1968$.

Ferrándiz Alborz, Jorge. El novelista hispanoamericano Jorge Icaza. Quito: Editora Quito, 1961.

García, Antonio. Sociología de la novela indigenista en el Ecuador; estructura social de la novelistica de Jorge Icaza. Quito: Casa de la Cultura Ecuatoriana, 1969. Orig. Revista Mexicana de Sociología, núm. 4 (1968), 901-932.

Garro, J. Eugenio. Jorge Icaza: vida y obra-bibliografía-antologí. New York: Instituto de las Españas en los Estados Unidos, 1947. Orig. Revista Hispánica Moderna, 13 (1947), 193-235.

Giberti, Eva. El complejo de Edipo en la literatura. Quito: Casa de la Cultura Ecuatoriana, 1964.

Ojeda, Enrique. Cuatro obras de Jorge Icaza. Quito: Casa de la Cultura Ecuatoriana, 1961.

Sackett, Theodore A. El arte en la novelistica de Jorge Icaza. Quito: Casa de la Cultura Ecuatoriana, 1974.

Articulos criticos:

Belmar, Daniel. «Huairapamushcas, novela de Jorge Icaza». Atenea, números 283-284 (1949), 140-141.

Campos, Jorge. "Novela americana, novela social: Horas de fiebre y Huasipungo». Insula, núm. 178 (1962), 14.

Dessau, Adalbert. «Icaza y Arguedas, exploradores del laberinto de los Andes». En Recopilación de textos sobre José Maria Arguedas (La Habana: Casa de las Américas, 1967), pp. 227-234.

Dulsey, Bernard M. «Icaza sobre Icaza». Modern Language Journal, 54 (1970), 233-245.

- «John Steinbeck and Jorge Icaza». American Book Collector, 18, 10 (1968), 15-17.

- «Jorge Icaza and his Ecuador». Hispania, 44 (1961), 99-102.

Durand, Luis. «Huasipungo, por Jorge Icaza», Atenea, 29 (1935), 127-129.

Ferrándiz Alborz, F. «El caso de América visto a través de una novela (Cholos)». Revista Americana, 4 (1945), 156-160.

Garro, J. Eugenio. «A través de las novelas de Jorge Icaza». Revista Hispánica Moderna, 12 (1946), 217-238. También Casa de la Cultura Ecuatoriana, 3, 6 (1948), 147-185.

González Rodas, Pablo. «Huasipungo, una novela ecuatoriana». Anales de la Universidad Central, núm. 350 (1967), 343-359.

Gutiérrez Girardot, Rafael. «Algunos problemas de la novela indigenista, a propósito de Jorge Icaza». En Primeras jornadas de lengua y literatura 
hispanoamericana (Salamanca: Universidad de Salamanca?, 1956), páginas 453-460. También en Juan Loveluck, comp. La novela hispanoamericana, 2. ${ }^{\text {a }}$ ed. (Santiago de Chile: Editorial Universitaria, 1966), pp. 221229.

Johnson, David D. «Huasipungo for children». Romance notes, 14 (1972), 41-43.

Larson, Ross F. «La evolución textual de Huasipungo de Jorge Icaza». Revista Iberoamericana, núm. 60 (1965), 209-222.

Lazo, Raimundo. «Jorge Icaza». En su La novela andina (México, D. F.: Porrúa, 1971), pp. 71-82.

Mújica, Elisa. «Huasipungo, por Jorge Icaza». En su El indio en América (Bogotá: Imprenta Municipal, 1948), 13-20.

Ojeda, J. Enrique. «Elementos picarescos en El chulla Romero y Flores, de Jorge Icaza». En La picaresca: orígenes, textos y estructuras (Madrid: Fundación Universitaria Española, 1979), pp. 1117-1122.

Ribadeneira M., Edmundo. «... Vigorosa presencia del indio». En su La novela ecuatoriana (México, D. F.: Fondo de Cultura Económica, 1948), pp. 198-202.

- «Una ojeada a la obra novelística de Jorge Icaza». Duquesne Hispanic Review, 2 (1963), 49-53. También Filosofía, letras y educación, núm. 33 (1966), 226-230.

Rodríguez-Luis, Julio. "Jorge Icaza». En su Hermenéutica y praxis del indigenismo (México, D. F.: Fondo de Cultura Económica, 1980), pp. 88-110.

Rojas, Angel F. «Jorge Icaza y Huasipungo». En su La novela ecuatoriana (México, D. F.: Fondo de Cultura Económica, 1948), pp. 198-202.

Sacoto, Antonio. «The intrinsic literary evaluation of Icaza's fiction». En su The Indian in the Ecuadorian novel (New York: Las Américas, 1967), pp. 169-228.

Salas Zamora, Edwin. «Notas sobre Icaza y Huasipungo». Repertorio latinoamericano, núm. 41 (1980), 7-12.

Spell, Jefferson Rea. «Jorge Icaza, defender of the Ecuadorian Indian». En su Contemporary Spanish-American fiction (Chapel Hill, N. C.: University of North Carolina Press, 1944), pp. 239-252.

Tapia, John Reyna. "Huasipungo». En su The Indian in the Spanish-American novel (Washington, D. C.: University Press of America, 1981), páginas 71-77.

Vetrano, Anthony J. «Imagery in two of Jorge Icaza's novels: Huasipungo and Huairapamushcas». Revista de Estudios Hispánicos, 6 (1972), 293-301. 
López Albújar, Enrique:

Obras:

Cuentos andinos. Lima: Imprenta de la «Opinión Nacional», 1920, etc.

Nuevos cuentos andinos. Lima: Ediciones «Peruanidad», 1937.

El hechizo de Tomaiquichua. Lima: Ediciones «Peruanidad», 1943.

\section{Bibliografías:}

«Biobibliografías de autores peruanos contemporáneos: Godofredo García, Enrique López Albújar». Boletín bibliográfico, 8, 1 (1938), 39-57.

Cornejo, Raúl Estuardo. «Bibliografía general de López Albújar». En Enrique López Albújar, Memorias (Lima, 1963), pp. 129-212. También como López Albújar, narrador de América: bibliografía general. Lima: P. L. Villanueva, 1963.

«Enrique López Albújar». Anuario bibliográfico peruano, 1964/1966, pp. 565. 612.

Estudios monográficos y disertaciones:

Cornejo, Raúl Estuardo. López Albújar, de «Miniaturas» (1895) a «Cuentos andinos» (1920). Tesis doctoral inédita, Universidad Nacional Mayor de San Marcos, 1962.

—. López Albújar, narrador de América: trayectoria vital. Madrid: Anaua, 1961.

Escajadillo, Tomás G. La narrativa de López Albújar. Lima: Consejo Nacional de la Universidad Peruana, 1972.

\section{Ensayos críticos:}

Arias-Larreta, Abraham. «Don Enrique López Albújar». Nueva democracia, 41, 1 (1961) 98-101.

Carrillo, Francisco. «Los aciertos indigenistas de Enrique López Albújar». Revista Peruana de Cultura, núms. 11-12 (1967), 147-151.

Castro Arenas, Mario. «Enrique López Albújar». En su La novela peruana y la evolución social (Lima: Cultura y Libertad, 1965), pp. 155-167.

Frikart, F. F. «The short stories of Enrique López Albújar». Hispania, 27 (1944), 482-488.

Gómez Lance, Betty Rita. «El indio y la naturaleza en los cuentos de López Albújar». Revista Iberoamericana, núm. 49 (1960), 141-145.

La Negra, Santiago. «Enrique López Albújar y Ciro Alegría». Realidad, número 15 (1955), 4; núm. 16 (1955), 10. 
Tamayo Vargas, Augusto. «Enrique López Albújar». Revista Peruana de Cultura, núm. 6 (1965), 105-121. También en su 150 artículos sobre el Perú (Lima: Universidad Nacional Mayor de San Marcos, Facultad de Letras y Ciencias Humanas, Instituto de Literatura, 1966), pp. 478-482.

López y Fuentes, Gregorio:

Obras:

El indio. México, D. F.: Botas, 1935, etc.

Los peregrinos inmóviles. México, D. F.: Botas, 1944.

Tierra. México, D. F.: El Gráfico, Talleres de El Universal, 1932.

Estudios monográficos y disertaciones:

De Anda, Joseph. "The Indian in works of Gregorio López y Fuentes». Dissertation Abstracts International, 30 (1970), 4980A-4981A.

Fernández Agüera, Eustasio. La proyección social en las novelas de Gregorio López y Fuentes. México, D. F.: Universidad Nacional Autónoma de México, 1960.

Kattar, Jeannette. Gregorio López y Fuentes et son roman: «El indio». Dakar, Senegal: Centres des Hautes Études Afro-Ibéro-Américaines de l'Université de Dakar, 1969.

\section{Articulos críticos:}

Alegría, Fernando. «López y Fuentes: trayectoria y temas». En Recopilación de textos sobre la novela de la revolución mexicana (La Habana: Casa de las Américas, 1975), pp. 295-315.

Chumacero, Alí. «Gregorio López y Fuentes». Letras de México, 4, 9 (1943), $1-2$.

Córdoba Infante, Julia. «Las novelas de Gregorio López y Fuentes». Revista de la Asociación de Mujeres Graduadas de la Universidad de Puerto Rico, 4, 4 (1942), 17-21, 30.

Crow, John A. «El drama revolucionario mexicano [El indio]». Revista Hispánica Moderna, 5 (1939), 20-31.

González, Manuel Pedro. «Gregorio López y Fuentes». En su Trayectoria de la novela en México (México, D. F.: Botas, 1951), pp. 249-267.

Higuera, Ernesto. «Una novela social de Gregorio López y Fuentes [El indio]». En su Cuadrante rojo (México, D. F., 1939), pp. 149-152.

Marshall, Pauline. «La novela indianista de López y Fuentes». Acta Salmanticensia, 10, 1 (1956), 431-438.

Mate, Hubert E. «Social aspects of novels by López y Fuentes and Ciro Alegría». Hispania, 39 (1956), 287-292. 
Plaza, Galvarino. «[El indio]». Cuadernos hispanoamericanos, núms. 320-321 (1977), 546-547.

Revueltas, José. «Un testimonio sobre Gregorio López y Fuentes». El libro y el pueblo, núm. 25 (1967), 42-43.

Salazar Mallen, Rubén. «[El indio]». Atenea, núm. 127 (1935), 96-99.

Simard, J. C. «Los peregrinos inmóviles: un roman indigéniste qu'il importe de revaloriser». Reflexión, 2.a serie, 3-4 (1974-1975), 270-274.

Tapia, John Reyna. "El indio». En su The Indian in the Spanish-American novel (Washington, D. C.: University Press of America, 1981), pp. 66-71.

- "Tierra». En su The Indian in the Spanish-American novel (Washington, D. C.: University Press of America, 1981), pp. 90-102.

Torriente, Loló de la. «El indio y Huasteca en su tiempo». En Recopilación de textos sobre la novela de la Revolución mexicana (La Habana: Casa de las Américas, 1975), pp. 278-282.

- - "Tres momentos de un novelista». En Recopilación de textos sobre la novela de la Revolución mexicana (La Habana: Casa de las Américas, 1975), pp. 295-315.

\section{Mariátegui, José C'ARLos:}

Obras:

Obras completas. Lima: Amauta, 1959-1970.

Ideología y política. Lima: Biblioteca Amauta, 1969, etc.

7 ensayos de interpretación de la realidad peruana. Lima: Biblioteca Amauta, 1928 , etc.

\section{Bibliografias:}

Foster, David William. «A checklist of criticism on José Carlos Mariátegui». Los ensayistas, núms. 10-11 (1981), 231-257.

Mead, Robert G. "Bibliografía crítica de José Carlos Mariátegui». Revista Hispánica Moderna, 27 (1961), 138-142.

Rouillón, Guillermo. «Biobibliografía de José Carlos Mariátegui». Boletín bibliográfico, 22, núms. 1-4 (1952), 102-212.

- Biobibliografía de José Carlos Mariátegui. Lima: Universidad Nacional Mayor de San Marcos, 1963. 345 pp.

Estudios monográficos y disertaciones:

Chang-Rodríguez, Eugenio. Poética e ideología en José Carlos Mariátegui. Madrid: Porrúa Turanzas, 1983.

Moretič, Yerko. José Carlos Mariátegui y su concepción del realismo. Santiago de Chile: Universidad Técnica del Estado, 1970. 
Reinaga, César Augusto. El indio y la tierra en Mariátegui; contribuciones al análisis económico. Cuzco, 1959.

Valcárcel, Luis E.; Augusto Salazar Bondy, y Augusto Tamayo Vargas. El problema del indio. El proceso de la instrucción pública. El proceso de la literatura (en 7 ensayos...). Lima: Biblioteca Amauta, 1976. Cada ensayo viene firmado independientemente.

\section{Artículos críticos:}

Casetta, Giovanni. «Il problema indigeno dalla tradizione alla modernità: José Carlos Mariátegui». Nova americana, núm. 3 (1980), 101-140.

Díaz, Filiberto. "Mariátegui y los Siete ensayos: un estudio y comentario». Cuadernos Americanos, núm. 170 (1970), 152-166.

Díaz Rizzotto, Jaime. «José Carlos Mariátegui y las posibilidades del desarrollo no capitalista de la comunidad indígena peruana». Cuadernos Americanos, núm. 146 (1966), 173-205.

Doll, Ramón. «7 ensayos de interpretación de la realidad peruana, por José Carlos Mariátegui». Nosotros, núm. 239 (1939), 125-130.

Macera dall'Orso, Pablo. «Reflexiones a propósito de la polémica del indigenismo». Apuntes, 3, 6 (1977), 75-81.

Mantesanz, José Antonio. «Mariátegui, un indigenismo marxista». Revista de la Universidad de México, 27, 10 (1973), 25-30.

Mires, Fernando. «Los indios y la tierra o cómo concibió Mariátegui la revoIución en el Perú». Nueva sociedad, núm. 5 (1980), 61-84.

Reedy, Daniel R. «The Cohesive Influence of José Carlos Mariátegui on Peruvian Art and Politics». En Edward D. Terry, Artists and writers in the evolution of Latin America (Alabama: University of Alabama Press, 1969), pp. 137-149. Comentarios por Ray F. Broussard, pp. 149-153.

Sacoto, Antonio. «José Carlos Mariátegui». En su El indio en el ensayo de la América española (Cuenca, 1981), pp. 165-190.

Sylvers, Malcolm. «La influencia italiana en el marxismo de Mariátegui y en los Siete ensayos de interpretación de la realidad peruana». En Homenaje a Jorge Basandre (Lima: Pontificia Universidad Católica del Perú, 1978), II, 313-332.

Tamayo Vargas, Augusto. «Mariátegui y la cultura peruana». En su 150 artículos sobre el Perú (Lima: Universidad Nacional Mayor de San Marcos, Facultad de Letras y Ciencias Humanas, Instituto de Literatura, 1966), pp. 495-500. También en Instituto Internacional de Literatura Iberoamericana, La cultura y la literatura iberoamericanas (México, D. F.: Ediciones de Andrea, y Berkeley: University of California Press, 1957), pp. 175182.

Tauro, Alberto. «El indigenismo de José Carlos Mariátegui». Nueva democracia, 17, 4 (1936), 25-26.

Vanden, Harry E. «The peasants as a revolutionary class: an early Latin American view». JIAS, 20, 2 (1978), 191-209. 
- «Socialism, land and the indians in the 7 ensayos». Inti, núm. 4 (1976), 71-75.

Wise, David Oakley. «A Peruvian 'indigenista' forum of the 1920's: José Carlos Mariátegui's Amauta». Ideologies and literature, núm. 13 (1980), 70-104.

Scorza, Manuel:

Obras:

Cantar de Agapito Robles. Barcelona: Monte Avila, 1978.

Historia de Garabombo, el invisible. Barcelona: Planeta, 1972. Reeditada en 1977 como Garabombo, el invisible.

El jinete insomne. Barcelona: Monte Avila, 1978.

Redoble por Rancas; lo que sucedió antes que el coornel Marroquín fundara el segundo cementerio de Chinche. Caracas: Monte Avila, 1977.

La tumba del relámpago (quinto cartar). Madrid: Siglo Veintiuno, 1979.

Ensayos criticos:

Acutis, Cesare. «Manuel Scorza, il mito e la storia». Nuovi argomenti, 38-39 (1974), 175-187.

Albertocchi, Giovanni. «Manuel Scorza: il quinto cantare peruviano: verso la soluzione del mito». Ponte, 37 (1981), 446-453.

Brady, Fabienne. «Scorza: entre la desilusión y la polémica lLa tumba del relámpago]». Revista de la Universidad de México, 33, 8 (1979), 49-51.

Correa Camiroaga, José. «Redoble por Rancas: ¿epopeya latinoamericana?». En Actas del Simposio Internacional de Estudios Hispánicos (Budapest: Akadémia Kiadó, 1978), pp. 509-515.

Echevarría, Evelio. "La narrativa de Manuel Scorza». En In honor of Boyd G. Carter (Laramie: University of Wyoming, Department of Modern and Classical Languages, 1981), pp. 17-23.

Escajadillo, Tomás G. «Scorza antes de la última batalla». Revista de Crítica Literaria Latinoamericana, núms. 7.8 (1978), 183-191.

Losada Guido, Alejandro. «Manuel Scorza. La creación literaria y el cambio social en el Perú». En su Creación y praxis... (Lima: Universidad Nacional Mayor de San Marcos, Dirección de Biblioteca y Publicaciones, 1976), pp. 106-118.

«Manuel Scorza: 'Yo viajo del mito a la realidad'». Crisis, núm. 12 (1974), $40-42,49$.

Prenz, Juan Octavio. «Nota a Scorza». Hispamérica, núm. 17 (1977), 107-110.

Tamayo Vargas, Augusto. «Manuel Scorza y un neoindigenismo». Cuadernos Hispanoamericanos, núm. 300 (1975), 689-693. 
Teja, Ada. «El mito en Redoble por Rancas: su función social». Annali, Istituto Universitario, Napoli. Sezione Romanica, 20 (1978), 257-278.

Tobin, Patricia. "The slow anger of improvidence [Redoble por Rancas]». Review, núm. 21-22 (1978), 175-177.

Vidal, Virginia. «América en los cantares de Manuel Scorza». Araucaria de Chile, núm. 10 (1980), 179-187.

VASCONCELOS, José:

Obras:

Obras completas. México, D. F.: Libreros Mexicanos Unidos, 1957-1961.

Indología; una interpretación de la cultura iberoamericana. París: Agencia Mundial de Librería, 1927?, etc.

Raza cósmica: misión de la raza iberoamericana; notas de un viaje a la América del Sur. Barcelona, 1925, etc.

Bibliografias:

Arce, David N.: Bibliografía de José Vasconcelos. México, D. F.: Biblioteca Nacional, 1958. Originalmente como «Bibliografías mexicanas contemporáneas, 6: José Vasconcelos». Boletín de la Biblioteca Nacional, 2. época, 8, 4 (1957), 33-44.

Foster, David William. «A checklist of criticism on José Vasconcelos». Los ensayistas, núms. 14-15 (1983), 177-212.

Sierra, Carlos J. «José Vasconcelos: hemerografía». Boletín bibliográfico de la Secretaria de Hacienda y Crédito Público, núm. 311 (1965), $2-34$.

Monografías y disertaciones:

Ahumada, Herminio. Los fundamentos sociológicos de la raza síntesis: Lester F. Ward y José Vasconcelos. México, D. F.: Imprenta Juan Pablos, 1930.

Beer, Gabriella de. José Vasconcelos and his world. New York: Las Américas, 1966.

Haddox, John H. Vasconcelos of Mexico, philosopher and prophet. Austin: University of Texas Press, 1967.

Sánchez Villaseñor, José. El sistema filosófico de Vasconcelos. México, D. F.: Polis, 1939.

Artículos críticos:

Beer, Gabriella de. «La raza cósmica: an ethical and scientific consideration». Revista Interamericana de Bibliografía, 25 (1975), 35-40. 
Carrión, Benjamín. «José Vasconcelos». En su Los creadores de la nueva América (Madrid: Sociedad General Española de Librería, 1928), pp. 21-76.

Cosco Montaldo, J. Oscar. «El Uruguay desfigurado al través de Vasconcelos; observaciones al margen de La raza cósmica». Nosotros, núm. 207 (1926), 494-516.

Deambrosis Martins, Carlos. «Una obra genial: La raza cósmica de Vasconcelos». Cuba contemporánea, 40 (1926), 80-99.

Fell, Claude. «Éléments de recherche pour la synthèse de La raza cósmica de José Vasconcelos». En Annales du Septième Congrès de la Société des Hispanistes Français (Rennes, 1973), pp. 123-145.

Jaén, Didier T. «La era estética en La raza cósmica de Vasconcelos». En Instituto Internacional de Literatura Iberoamericana, XVII Congreso (Madrid: Cultura Hispánica del Centro Iberoamericano de Cooperación, 1978), pp. 1511-1517.

- «Introduction». En José Vasconcelos, La raza cósmica/The cosmic race (Los Angeles: California State University, Department of Chicago Studies, Centro de Publicaciones, 1979), pp. xi-xxxv.

__. "La raza cósmica de Vasconcelos: una re-evaluación». Texto crítico, núm. 1 (1975), 14-21.

Mariátegui, José Carlos. «Indología, por José Vasconcelos». En su Temas de nuestra América (Lima: Biblioteca Amauta, 1960), pp. 78-84.

- «[Vasconcelos]». En su Crítica literaria (Buenos Aires: Jorge Alvarez, 1969), pp. 59-75.

Mistral, Gabriela. "La indología de Vasconcelos». Revista de Filosofia, 13 (1927), 305-309.

Monsiváis, Carlos. «José Vasconcelos: la búsqueda del paraíso perdido». Comunidad, núm. 14 (1968), 347-355.

Parr, Carmen Salazar. «José Vasconcelos: thought and ideology in the Chicano literary arts». Denver Quarterly, 16, 3 (1981). 52-60.

Posada, Germán. «La idea de América en Vasconcelos». Historia mexicana, núm. 47 (1963), 379-403.

Prieto, José María. «Balance del pensamiento de José Vasconcelos». Estudios americanos, núms. 98-99 (1959), 269-275.

Sacoto, Antonio. «Aspectos indigenistas en la obra literaria de José Vasconcelos». Cuadernos Americanos, núm. 163 (1969), 151-157.

- - «José Vasconcelos». En su El indio en el ensayo de la América española (Cuenca, 1981), pp. 154-165.

Vera y Cuspinera, Margarita. «José Vasconcelos, profeta de la 'raza cósmica'». Latino América, núm. 8 (1975), 191-202.

Villalobos Domínguez, C. «[Indölogía]». Nosotros, núm. 216 (1927), 273-277.

Villegas, Abelardo. «José Vasconcelos». En su La filosofía de lo mexicano (México, D. F.: Fondo de Cultura Económica, 1960), pp. 65-99. 